\title{
Evidence of Sibling Species in the Brown Planthopper Complex (Nilaparvata lugens) Detected from Short and Long Primer Random Amplified Polymorphic DNA Fingerprints
}

\begin{abstract}
The inheritance of 31 amplicons from short and long primer RAPD was tested for segregating ratios in two families of the brown planthopper,Nilaparvata lugens, and they were found to be inherited in a simple Mendelian fashion. These markers could now be used in population genetics studies of $\mathrm{N}$. lugens. Ten populations of $\mathrm{N}$. lugens were collected from five locations in Malaysia. Each location had two sympatric populations. Cluster and principal coordinate analyses based on genetic distance along with AMOVA revealed that the rice-infesting populations (with high esterase activity) at five localities clustered together as a group, and Leersia-infesting populations (with low esterase activity) at the same localities formed another distinct cluster. Two amplicons from primers OPD03 $(0.65 \mathrm{~kb})$ and peh\#6 $(1.0 \mathrm{~kb})$ could be considered diagnostic bands, which were fixed in the Leersia-infesting populations. These results represent evidence of a sibling species in the N. lugens complex.
\end{abstract}

Keyword: Rice brown planthopper, Nilaparvata lugens, Short and long primer RAPD-PCR, Sibling species 